\title{
Goiabeira 'Paluma' sob diferentes sistemas de cultivo, épocas e intensidades de poda de frutificação
}

\author{
Luiz Augusto Lopes Serrano(1), Cláudia Sales Marinho(2), Cláudio Pagotto Ronchi(1), Inorbert de Melo Lima ${ }^{(1)}$, \\ Marlon Vagner Valentim Martins ${ }^{(1)}$ e Flávio Dessaune Tardin ${ }^{(3)}$
}

\begin{abstract}
(1) Instituto Capixaba de Pesquisa, Assistência Técnica e Extensão Rural, Rodovia BR 101 norte, Km 151, Caixa Postal 62, CEP 29900-970 Linhares, ES. E-mail: lalserrano@incaper.es.gov.br, pagotto@incaper.es.gov.br, inorbert@incaper.es.gov.br, mvalentim@incaper.es.gov.br (2)Universidade Estadual do Norte Fluminense Darcy Ribeiro, Av. Alberto Lamego 2.000, Horto, CEP 28013-602 Campos dos Goytacazes, RJ. E-mail marinho@uenf.br ${ }^{(3)}$ Embrapa Milho e Sorgo, Rodovia MG 424, Km 45, CEP 35701-970 Sete Lagoas, MG. E-mail: tardin@cnpms.embrapa.br
\end{abstract}

Resumo - O objetivo deste trabalho foi avaliar a produção e a qualidade dos frutos da goiabeira 'Paluma', em diferentes sistemas de cultivo, épocas e intensidades de poda de frutificação, em Pedro Canário, ES. O delineamento experimental foi o de blocos ao acaso, em esquema de parcelas sub-subdivididas. As parcelas foram os sistemas de cultivo irrigado e sequeiro; as subparcelas foram as épocas de poda (10/11/2005, 9/12/2005, 13/1/2006 e 10/2/2006); e as sub-subparcelas foram as intensidades de poda (curta, média e longa). A produção, o número de frutos e o peso médio dos frutos foram maiores nas plantas cultivadas com irrigação. Independentemente da época de poda, as plantas submetidas à poda curta apresentaram as menores produções e números de frutos por planta, entretanto produziram os frutos mais pesados. As maiores produções e número de frutos por planta ocorreram nas plantas submetidas às podas médias e longas, em fevereiro, enquanto os frutos mais pesados, independentemente da intensidade da poda, foram produzidos pelas plantas podadas em dezembro. O teor de sólidos solúveis totais (SST), acidez total titulável (ATT) e relação SST/ATT dos frutos não foram influenciados pela intensidade da poda de frutificação, porém foram influenciados pelo sistema de cultivo e a época de poda.

Termos para indexação: Psidium guajava, irrigação, sólidos solúveis totais, acidez total titulável, peso de frutos.

\section{'Paluma' guava trees under different cultivation systems, times and intensities of fructification pruning}

\begin{abstract}
The objective of this work was to evaluate the effects of different fructification pruning times and intensities on the yield and fruit quality of 'Paluma' guava trees in two cultivation systems, in Pedro Canário, ES, Brazil. The experimental design was a randomized complete blocks in a split split plots scheme. The main plots were the cultivated systems (with and without irrigation), the split plots were the pruning times (November 10, 2005; December 9, 2005; January 13, 2006; and February 10, 2006), and the split split plots were the pruning intensities (heavy, medium and light). Plant yield, number of harvested fruits, and fruits medium weight were higher in irrigated plants. Independently of pruning time, plants subjected to heavy pruning provided the smallest yield and number of fruits per plant, however produced the higher fruit weight. The largest yield and number of fruits per plant occurred in plants subjected to medium and light pruning in February, while higher fruit weight occurred in plants pruned in December, regardless pruning intensity. Total soluble solids, titratable acidity and ratio were not affected by pruning intensity; however, those characteristics were affected by cultivate systems and pruning time.
\end{abstract}

Index terms: Psidium guajava, irrigation, total soluble solids, titratable acidity, fruit weight.

\section{Introdução}

O Pólo de Produção de Goiaba para Indústria, no Estado do Espírito Santo, foi criado em 2003 no Município de Pedro Canário. Com a meta de alcançar uma produção em torno de 10,5 mil toneladas anuais, foram plantadas 120 mil mudas da goiabeira 'Paluma', em área de 300 ha.
No Brasil, a goiabeira é cultivada em três sistemas de produção bastante distintos: cultura de goiaba de mesa, cultura de goiaba para a indústria e cultura mista. Este último visa atender os dois mercados simultaneamente, o que é interessante para os produtores, uma vez que os frutos de melhor qualidade são destinados ao mercado de fruta in natura, que alcança melhores preços, e o restante é destinado ao 
processamento, nas diferentes formas, de acordo com o tipo de fruto (Piza Júnior, 1994; Gonzaga Neto et al., 2001).

A característica fundamental do sistema de produção com cultura mista é a utilização de um método de poda, denominado poda de frutificação, que possibilita a obtenção de frutos ao longo de todo o ano, quando associado à irrigação e ao manejo adequado da adubação (Piza Júnior, 1994). Embora a goiabeira responda satisfatoriamente à poda de frutificação, dois aspectos de fundamental importância devem ser considerados: a época e a intensidade da poda (Gonzaga Neto et al., 2001). A realização de podas, em épocas e intensidades impróprias, pode afetar negativamente a produção de goiabas, fato constatado por Gonzalez \& Sourd (1982) e Singh et al. (2001).

Os frutos da goiabeira 'Paluma' são destinados à industrialização, pois possuem características para o processamento, para a elaboração de sucos, compotas e doces em pasta, entretanto, em razão da qualidade, seus frutos também podem ser consumidos in natura, $\mathrm{o}$ que a torna uma opção para a cultura mista (Pereira \& Nachtigal, 2002).

Pesquisas e recomendações sobre a irrigação na cultura da goiabeira são escassas, porém indicam aumentos de produtividade com o aumento da lâmina de irrigação aplicada (Sousa, 1997; Chirinos-Torres et al., 2006). A falta de água disponível no solo, em época de elevada necessidade hídrica pela goiabeira, quando surgem novas brotações de ramos e folhas, durante o período de intenso florescimento, fixação e desenvolvimento dos frutos, pode resultar em frutos pequenos e em menor produção por planta (Manica et al., 2000).

Este trabalho teve como objetivo avaliar as características de produção e de qualidade dos frutos da goiabeira 'Paluma', produzidos em plantas com e sem irrigação, submetidas a diferentes intensidades de poda de frutificação, em diferentes épocas do ano.

\section{Material e Métodos}

O experimento foi realizado no distrito de Cristal do Norte, Município de Pedro Canário, região Norte do Estado do Espírito Santo, a 18¹7'33"S, 3957'26"W e $65 \mathrm{~m}$ de altitude. A região é classificada, segundo Köppen, como tropical chuvosa e clima de bosque (Am). O solo é classificado como Argissolo Amarelo distrófico. Os valores mensais de precipitação efetiva e de temperatura média do município, durante o experimento, são apresentados na Figura 1.
Em novembro de 2005, foi selecionada uma área de goiabeiras 'Paluma', com 15 meses de idade, em espaçamento $6,5 \times 4 \mathrm{~m}$, advindas de mudas certificadas formadas via estaquia. Até a implantação do experimento, essas plantas ainda não haviam sido submetidas à poda de frutificação.

$\mathrm{O}$ experimento foi realizado em delineamento de blocos ao acaso, com quatro repetições, e os tratamentos foram distribuídos em esquema de parcelas subsubdivididas, com as parcelas compostas pelos sistemas de cultivo irrigado e sequeiro, as subparcelas pelas épocas de poda (10/11/2005,9/12/2005, 13/1/2006 e 10/2/2006), e as sub-subparcelas pelas intensidades da poda de frutificação (curta, média e longa).

As intensidades da poda de frutificação foram classificadas quanto à distância em que os ramos foram podados a partir da base, em: curta ou drástica (podados a $1 \mathrm{~cm}$ da base), média (podados a $1 / 3 \mathrm{de}$ seu comprimento, a partir da base), e longa ou desponte (podados a 2/3 de seu comprimento, a partir da base). Todos os ramos de crescimento da planta foram podados sem se considerar seu diâmetro. Durante a realização da poda, foram eliminados todos os frutos e flores presentes nas plantas.

Para cada sistema de cultivo, foram selecionadas quatro linhas de plantas localizadas na parte central do pomar, com presença de bordadura. No centro dessas linhas foram selecionadas 12 plantas, consideradas homogêneas em relação à idade, à altura da planta, à conformação da copa (um tronco principal com três pernadas), e à sanidade e vigor (plantas aparentemente sadias e sem sintomas foliares de deficiência nutricional). Cada linha de plantas representou uma época de poda

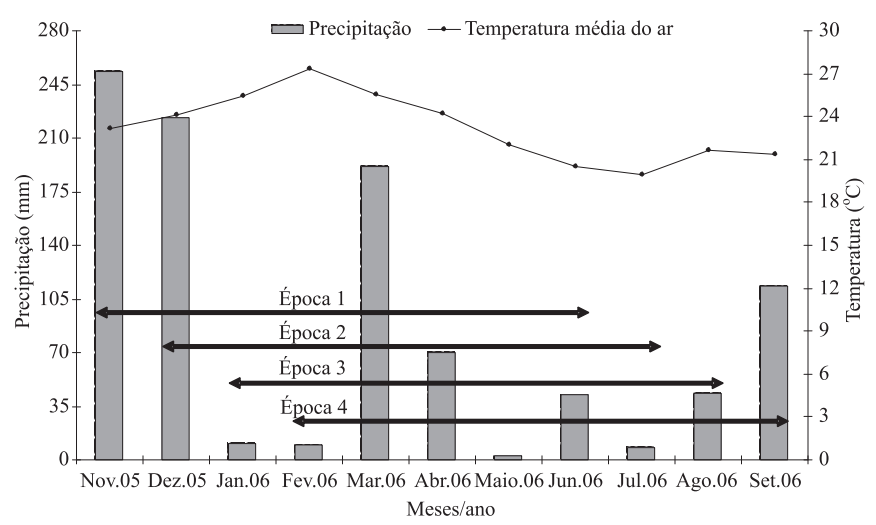

Figura 1. Dados climáticos do Município de Pedro Canário, ES, no período de realização do experimento. 
de frutificação e foi dividida em quatro grupos com três plantas, que foram submetidos às três intensidades de poda de frutificação.

Foram coletadas amostras dos solos nas áreas dos dois sistemas de cultivo, para a realização de análises químicas e físicas. No cultivo de sequeiro, o pH do solo em água às profundidades 0 a 20 e 21 a $40 \mathrm{~cm}$ foi, respectivamente, de 4,9 e 4,6; a capacidade de troca de cátions em $\mathrm{pH} 7$ (T) foi de 5,43 e $5,13 \mathrm{cmol}_{\mathrm{c}} \mathrm{dm}^{-3}$; e a saturação por bases (V) de $40,33 \mathrm{e} 49,51 \%$. No cultivo irrigado, o $\mathrm{pH}$ do solo em água, às mesmas profundidades foi, respectivamente, de 5,3 e 5,1; a capacidade de troca de cátions em $\mathrm{pH} 7$ foi de $5,44 \mathrm{e}$ $4,99 \mathrm{cmol}_{\mathrm{c}} \mathrm{dm}^{-3}$; e a saturação por bases de 40,44 e 48,10\%. Quanto à textura, o solo de toda a área foi classificado como franco arenoso, na camada de 0 a $20 \mathrm{~cm}$ de profundidade, e franco argilo-arenoso na camada de 21 a $40 \mathrm{~cm}$ de profundidade.

Para cada época de poda, foram coletadas amostras para análises químicas foliares, quando as plantas estavam em pleno florescimento, conforme Natale et al. (1996).

A interpretação dos resultados das análises químicas e as recomendações de calagem e adubação foram feitas de acordo com Natale et al. (1996). O calcário dolomítico, o superfosfato simples e a matéria orgânica foram aplicados antes da poda de frutificação, e o adubo NPK 30-0-20 foi aplicado, parceladamente, a partir do florescimento (70 a 77 dias após a poda).

O sistema de irrigação utilizado foi o de microaspersão (um emissor por planta), com vazão aproximada de $45 \mathrm{~L} \mathrm{~h}^{-1}$. Com exceção dos dias chuvosos, a irrigação foi realizada diariamente, tendo-se deixado o sistema ligado por uma hora. Esse manejo corresponde ao mais praticado pelos produtores do pólo.
Foram necessárias pulverizações para o controle químico de plantas daninhas, para prevenção e controle da ferrugem (Puccinia psidii), e para o controle do psilídeo (Triozoida sp.).

No período da colheita dos frutos, entre 182 e 238 dias após a poda, foram colhidos todos os frutos de cada planta, para a determinação da produção total por planta, do número de frutos por planta e do peso médio dos frutos. Os frutos colhidos foram pesados individualmente em balança analítica digital, com precisão de $0,01 \mathrm{~g}$.

Durante a colheita dos frutos produzidos após a poda de cada época, selecionaram-se, em cada tratamento, 12 frutos maduros (coloração da casca amarela e polpa vermelha) e 12 frutos no estádio "de vez" (fruto completamente desenvolvido com coloração da casca verde-clara e polpa rósea). Em seguida, foram determinados os teores de sólidos solúveis totais (SST), a acidez total titulável (ATT) e a razão SST/ATT (ratio). O teor de SST foi determinado por leitura direta em refratômetro de mesa, e a ATT por titulação em $\mathrm{NaOH} 0,1 \mathrm{~N}$.

Os dados obtidos foram submetidos à análise de variância, e as médias foram comparadas pelo teste de Tukey, a 5\% de probabilidade. Também foi realizada a correlação entre as características avaliadas. Todas as análises foram feitas com o programa estatístico SAEG 9.0 (UFV, 2005).

\section{Resultados e Discussão}

O sistema de cultivo, a época de poda e a intensidade da poda de frutificação influenciaram a produção de frutos, o número de frutos colhidos e o peso médio dos frutos (Tabela 1). Para essas três características, as

Tabela 1. Características de produção da goiabeira 'Paluma', em dois sistemas de cultivo, submetida a diferentes épocas e intensidades de poda de frutificação ${ }^{(1)}$.

\begin{tabular}{|c|c|c|c|c|c|c|c|c|c|}
\hline \multirow[t]{2}{*}{ Tratamento } & \multicolumn{3}{|c|}{ Produção de frutos (kg por planta) } & \multicolumn{3}{|c|}{$\mathrm{N}^{0}$ de frutos colhidos por planta } & \multicolumn{3}{|c|}{ Peso médio de frutos $(\mathrm{g})$} \\
\hline & Irrigado & Sequeiro & Média & Irrigado & Sequeiro & Média & Irrigado & Sequeiro & Média \\
\hline \multicolumn{10}{|l|}{ Época de poda } \\
\hline $10 / 11 / 2005$ & $20,33 \mathrm{Ab}$ & $13,58 \mathrm{Bc}$ & $16,95 \mathrm{c}$ & $117,92 \mathrm{Ac}$ & $89,25 \mathrm{Ac}$ & $103,58 \mathrm{c}$ & $176,92 \mathrm{Ab}$ & $154,95 \mathrm{Bc}$ & $165,93 \mathrm{c}$ \\
\hline $09 / 12 / 2005$ & $46,04 \mathrm{Aa}$ & $20,71 \mathrm{Bb}$ & $33,37 b$ & $236,08 \mathrm{Ab}$ & $101,67 \mathrm{Bbc}$ & $168,88 \mathrm{~b}$ & $196,11 \mathrm{Ba}$ & $205,45 \mathrm{Aa}$ & $200,78 \mathrm{a}$ \\
\hline $13 / 01 / 2006$ & $40,80 \mathrm{Aa}$ & $22,63 \mathrm{Bb}$ & $31,72 b$ & $211,42 \mathrm{Ab}$ & $132,58 \mathrm{Bb}$ & $172,00 \mathrm{~b}$ & $195,81 \mathrm{Aa}$ & $174,54 \mathrm{Bb}$ & $185,17 b$ \\
\hline $10 / 02 / 2006$ & $46,58 \mathrm{Aa}$ & $31,84 \mathrm{Ba}$ & $39,21 \mathrm{a}$ & $279,58 \mathrm{Aa}$ & $267,58 \mathrm{Aa}$ & $273,58 \mathrm{a}$ & $174,83 \mathrm{Ab}$ & $126,06 \mathrm{Bd}$ & $150,45 \mathrm{~d}$ \\
\hline \multicolumn{10}{|c|}{ Intensidade de poda } \\
\hline Curta & $20,18 \mathrm{Ac}$ & $14,25 \mathrm{Bb}$ & $17,22 \mathrm{c}$ & $101,06 \mathrm{Ac}$ & $80,94 \mathrm{Ab}$ & $91,00 \mathrm{c}$ & $199,83 \mathrm{Aa}$ & $181,59 \mathrm{Aa}$ & $190,71 \mathrm{a}$ \\
\hline Média & $44,73 \mathrm{Ab}$ & $24,77 \mathrm{Ba}$ & $34,75 b$ & $251,44 \mathrm{Ab}$ & $170,62 \mathrm{Ba}$ & $211,03 b$ & $178,77 \mathrm{Aa}$ & $158,10 \mathrm{Aa}$ & $168,43 b$ \\
\hline Longa & $50,39 \mathrm{Aa}$ & $27,55 \mathrm{Ba}$ & $38,97 \mathrm{a}$ & $281,25 \mathrm{Aa}$ & $191,75 \mathrm{Ba}$ & $236,50 \mathrm{a}$ & $179,15 \mathrm{Aa}$ & $156,07 \mathrm{Aa}$ & $167,61 \mathrm{~b}$ \\
\hline Média & $38,44 \mathrm{~A}$ & $22,19 \mathrm{~B}$ & 30,31 & $211,25 \mathrm{~A}$ & $147,77 \mathrm{~B}$ & 179,51 & $185,92 \mathrm{~A}$ & $165,25 B$ & 175,58 \\
\hline CV $(\%)$ & & & 15,84 & & & 15,92 & & & 3,67 \\
\hline
\end{tabular}

(1)Médias seguidas por letras iguais, maiúsculas nas linhas e minúsculas nas colunas, dentro das mesmas épocas e intensidades de poda, não diferem entre si pelo teste de Tukey, a $5 \%$ de probabilidade. 
maiores médias foram observadas nas plantas do sistema de cultivo irrigado, e a diferença na produção de frutos foi de $16,25 \mathrm{~kg}$ por planta $\left(6.240 \mathrm{~kg} \mathrm{ha}^{-1}\right)$, equivalente a um acréscimo de $73 \%$ na produção. Sousa (1997), no Norte Fluminense, constatou que goiabeiras 'Ogawa 3' sem irrigação tiveram tanto a produção como o número de frutos reduzidos em relação às plantas irrigadas.

As boas produções observadas podem estar associadas ao clima favorável da região e ao estado nutricional das plantas, visto que os teores foliares dos nutrientes (Tabela 2), exceto para magnésio e cobre, estiveram dentro ou acima da faixa adequada (Natale et al., 1996). Gonzaga Neto et al. (2001) afirmam que a primeira safra da goiabeira 'Paluma', a partir de aproximadamente 12 a 14 meses após o plantio no campo, em áreas irrigadas do Nordeste, pode atingir até $15 \mathrm{~kg}$ de fruto por planta.

No sistema irrigado, as maiores produções foram decorrentes das podas realizadas em dezembro, janeiro e fevereiro, e quando se praticou a poda longa (Tabela 1). No sistema de sequeiro, as maiores produções foram decorrentes da poda realizada em fevereiro, nas plantas submetidas às podas média e longa. Esses resultados contrastam com os obtidos por Lopes et al. (1984), que não verificaram efeito da época da poda sobre a produção da goiabeira 'IAC-4', em cultivo de sequeiro no Estado do Rio Grande do Sul, fato associado ao clima frio daquela região.

Apesar de o número de frutos por planta ser maior no sistema irrigado, nas podas realizadas em novembro e fevereiro não houve diferença entre os sistemas (Tabela 1). Antes da realização da poda nessas duas épocas, houve um período de deficit hídrico que pode ter favorecido maior produção de flores do sistema de sequeiro, fato já observado em goiabeiras na Índia (Singh et al., 1997). Segundo Larcher (2000), a paralisação do crescimento vegetativo, em razão da ocorrência de seca, resulta no acúmulo de carboidratos de reservas pelas plantas, que são utilizados posteriormente durante o florescimento.

Nos dois sistemas de cultivo, o maior número de frutos colhidos foi observado nas plantas podadas em fevereiro (Tabela 1). No sistema irrigado, o maior número de frutos colhidos ocorreu nas plantas submetidas à poda longa, enquanto no sistema de sequeiro ocorreu nas plantas submetidas às podas média e longa.

Em todas as épocas de poda, com exceção da realizada em dezembro, os maiores pesos médios de frutos foram obtidos pelas plantas cultivadas com irrigação (Tabela 1). O menor número de frutos, associado à precipitação ocorrida entre março e junho (Figura 1), pode ter favorecido a produção de frutos mais pesados nas plantas em sequeiro, podadas em dezembro.

Houve interação significativa entre as épocas e as intensidades de poda para as características de produção. Plantas submetidas às podas média e longa em fevereiro apresentaram as maiores produções e número de frutos por planta, entretanto produziram frutos de menor peso médio (Tabela 3). As plantas submetidas à poda longa apresentaram a maior produção e o maior número de frutos colhidos por planta, em todas as épocas de poda, fato este também observado por Garcia \& Pérez-Pérez (1977) na goiabeira 'Corriente', entretanto não houve diferença em relação às plantas submetidas à poda média em novembro e fevereiro.

Para todas as intensidades de poda avaliadas, a produção de frutos mais pesados ocorreu nas plantas podadas em dezembro (Tabela 3 ). Em todas as épocas de poda, as plantas submetidas à poda curta apresentaram menores produções e número de frutos,

Tabela 2. Teores de nutrientes nas folhas das goiabeiras 'Paluma' avaliadas no experimento.

\begin{tabular}{|c|c|c|c|c|c|c|c|c|c|c|c|}
\hline \multirow[t]{2}{*}{ Época de poda } & $\mathrm{N}$ & $\mathrm{P}$ & $\mathrm{K}$ & $\mathrm{Ca}$ & $\mathrm{Mg}$ & $\mathrm{S}$ & $\mathrm{Zn}$ & $\mathrm{Fe}$ & $\mathrm{Mn}$ & $\mathrm{Cu}$ & B \\
\hline & & & & $\left.\mathrm{kg}^{-1}\right)-$ & & 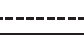 & & & $\left.\mathrm{mg} \mathrm{kg}^{-1}\right)$ & --.-- & ------- \\
\hline & \multicolumn{11}{|c|}{ Sequeiro } \\
\hline Novembro/2005 & 2,87 & 0,14 & 1,75 & 1,08 & 0,23 & 0,25 & 23,93 & 45,89 & 112,85 & 7,08 & 30,57 \\
\hline Dezembro/2005 & 2,59 & 0,15 & 1,63 & 1,42 & 0,45 & 0,26 & 26,95 & 47,42 & 89,93 & 9,00 & 23,37 \\
\hline Janeiro/2006 & 2,73 & 0,83 & 1,87 & 1,44 & 0,52 & 0,37 & 26,18 & 54,31 & 90,36 & 39,81 & 22,74 \\
\hline \multirow[t]{2}{*}{ Fevereiro/2006 } & 2,73 & 0,83 & 1,95 & 1,29 & 0,20 & 0,22 & 21,54 & 83,88 & 115,54 & 7,38 & 27,17 \\
\hline & \multicolumn{11}{|c|}{ Irrigado } \\
\hline Novembro/2005 & 2,80 & 0,15 & 1,90 & 1,15 & 0,29 & 0,41 & 39,56 & 67,49 & 101,50 & 12,70 & 34,11 \\
\hline Dezembro/2005 & 2,59 & 0,14 & 1,73 & 1,56 & 0,48 & 0,25 & 36,96 & 49,70 & 81,30 & 11,02 & 23,37 \\
\hline Janeiro/2006 & 2,38 & 0,76 & 1,92 & 1,19 & 0,27 & 0,28 & 25,94 & 46,55 & 59,76 & 14,40 & 20,66 \\
\hline Fevereiro/2006 & 2,80 & 0,88 & 2,50 & 1,37 & 0,21 & 0,21 & 22,23 & 58,92 & 168,48 & 8,48 & 27,73 \\
\hline
\end{tabular}


entretanto produziram frutos de maior peso médio. Esse comportamento também foi constatado com a prática do raleamento de frutos na goiabeira 'Rica' (Gonzaga Neto et al., 1997), e com a prática da poda nas goiabeiras 'Fan Retief' (Lötter, 1990) e 'JP-1' (Yunus, 1991).

Segundo Mika (1986), a poda severa estimula o crescimento vegetativo da planta, o que causa decréscimo no desenvolvimento das gemas frutíferas, um menor número de frutos e, conseqüentemente, redução na produção por planta. Contudo, como há um aumento na relação entre fonte e dreno de assimilados, isso pode contribuir para o maior tamanho e peso dos frutos. Hoque et al. (1989) observaram aumento do peso da goiaba 'Kazi Piara', em consequiência do aumento na relação entre folhas e frutos, com máximo peso na relação 125:1.

$\mathrm{O}$ número de frutos produzidos apresentou correlação linear positiva com a produção da planta $\left(r=0,93^{*}\right)$, e a mesma correlação não foi observada para o peso médio dos frutos. Isto explica porque as plantas submetidas à poda curta, apesar de produzirem frutos mais pesados, não obtiveram as maiores produções. Como os consumidores têm preferência por goiabas de tamanho médio a grande (Choudhury et al., 2001), a poda curta poderá servir como opção para os produtores que visam o mercado de fruta in natura.

Com relação às características qualitativas da goiaba 'Paluma', as médias gerais para SST, ATT e a relação
SST/ATT foram superiores às obtidas por Cavalini et al. (2006), em Vista Alegre do Alto, SP, e por Lima et al. (2002) em Petrolina, PE.

As intensidades de poda de frutificação não tiveram influência sobre as características qualitativas avaliadas, nos frutos colhidos tanto no estádio "de vez" (Tabela 4) quanto no estádio maduro (Tabela 5), fato também observado em goiabas 'JP-1' (Yunus, 1991) e 'Criolla Roja' (Quijada et al., 1999).

Nos frutos "de vez", os maiores teores de SST foram obtidos quando produzidos em plantas cultivadas no sistema de sequeiro, com exceção da poda realizada em dezembro, em que não foi constatada diferença entre os sistemas de cultivo (Tabela 4). Esses resultados são semelhantes aos observados por Singh et al. (1997), em goiabeiras 'Sardar' e 'Allahabad Safeda', cultivadas na Índia, e por Pereira (1996) em goiabeira 'Pirassununga Vermelha', cultivada em Visconde do Rio Branco, MG. Nesses trabalhos, verificou-se efeito favorável do deficit hídrico no solo sobre essa característica do fruto, fato atribuído à menor diluição dos SST.

No cultivo irrigado, não houve diferença no teor de SST dos frutos "de vez" e maduros, em relação às épocas de poda de frutificação (Tabelas 4 e 5). No cultivo em sequeiro, tanto os frutos "de vez" quanto os maduros, produzidos pelas plantas podadas em dezembro, apresentaram menores teores de SST.

Tabela 3. Efeito da interação entre épocas e intensidades de poda de frutificação, sobre as características de produção da goiabeira 'Paluma', em dois sistemas de cultivo ${ }^{(1)}$.

\begin{tabular}{lccc} 
Época de poda & \multicolumn{3}{c}{ Intensidade de poda } \\
\cline { 2 - 4 } & Curta & Média & Longa \\
\hline Novembro/2005 & $12,03 \mathrm{Bb}$ & Produção de frutos (kg por planta) & $19,75 \mathrm{Ac}$ \\
Dezembro/2005 & $21,10 \mathrm{Ca}$ & $19,08 \mathrm{Ac}$ & $42,78 \mathrm{Ab}$ \\
Janeiro/2006 & $15,84 \mathrm{Cab}$ & $36,24 \mathrm{Bb}$ & $43,19 \mathrm{Ab}$ \\
Fevereiro/2006 & $19,91 \mathrm{Bab}$ & $36,13 \mathrm{Bb}$ & $50,17 \mathrm{Aa}$ \\
\hline & & $47,55 \mathrm{Aa}$ & $123,50 \mathrm{Ac}$ \\
Novembro/2005 & $65,88 \mathrm{Bb}$ & $\mathrm{N}$ de frutos colhidos por planta & $219,50 \mathrm{Ab}$ \\
Dezembro/2005 & $103,62 \mathrm{Ca}$ & $121,38 \mathrm{Ac}$ & $237,50 \mathrm{Ab}$ \\
Janeiro/2006 & $80,12 \mathrm{Cab}$ & $183,50 \mathrm{Bb}$ & $365,50 \mathrm{Aa}$ \\
Fevereiro/2006 & $114,38 \mathrm{Ba}$ & $198,38 \mathrm{Bb}$ & $158,14 \mathrm{Bc}$ \\
Novembro/2005 & & $340,88 \mathrm{Aa}$ & $196,07 \mathrm{Ba}$ \\
Dezembro/2005 & $182,87 \mathrm{Ac}$ & Peso médio de frutos $(\mathrm{g})$ & $178,66 \mathrm{Bb}$ \\
Janeiro/2006 & $206,34 \mathrm{Aa}$ & $156,79 \mathrm{Bc}$ & $199,93 \mathrm{ABa}$ \\
Fevereiro/2006 & $197,14 \mathrm{Ab}$ & $179,73 \mathrm{Bb}$ & $137,57 \mathrm{Bd}$ \\
\hline
\end{tabular}

${ }^{(1)}$ Médias seguidas por letras iguais, maiúsculas nas linhas e minúsculas nas colunas, não diferem entre si pelo teste de Tukey, a 5\% de probabilidade. 
Nos frutos maduros, houve diferença entre os sistemas de cultivo para o teor de SST, nos frutos produzidos pelas plantas podadas em dezembro, em que o maior teor foi observado no cultivo irrigado, e em fevereiro, em que o maior teor foi observado no cultivo em sequeiro. No cultivo em sequeiro, a maior média do teor de SST, nos frutos maduros, foi observada nas plantas podadas em novembro e fevereiro.

No cultivo irrigado, a ATT dos frutos "de vez" e dos maduros foi maior nas plantas podadas em novembro e dezembro (Tabelas 4 e 5). Segundo Silva et al. (2006), temperaturas baixas durante a maturação contribuem para a ocorrência de frutos ácidos, e esse fato foi observado nos períodos de maturação das duas primeiras épocas de poda (Figura 1). Entretanto, no cultivo em sequeiro, não houve diferença na ATT dos frutos, em relação às épocas de poda.

Diferenças entre a ATT dos frutos "de vez", com relação aos sistemas de cultivo, foram observadas nas épocas de poda novembro e fevereiro (Tabela 4). Nas plantas podadas em novembro, o maior valor foi observado nos frutos das plantas em cultivo irrigado, e em fevereiro, o maior valor foi observado nos frutos das plantas em cultivo de sequeiro. Nos frutos maduros, houve diferença apenas quando a poda foi realizada em fevereiro, em que o maior valor de ATT também ocorreu nos frutos produzidos no sistema de sequeiro (Tabela 5).

Tabela 4. Características de qualidade dos frutos da goiabeira 'Paluma', colhidos no estádio "de vez", em dois sistemas de cultivo, submetida a diferentes épocas e intensidades de poda de frutificação(1).

\begin{tabular}{|c|c|c|c|c|c|c|c|c|c|}
\hline \multirow[t]{2}{*}{ Tratamento } & \multicolumn{3}{|c|}{$\begin{array}{c}\text { Teores de sólidos solúveis } \\
\left({ }^{\circ} \text { Brix }\right)\end{array}$} & \multicolumn{3}{|c|}{$\begin{array}{c}\text { Acidez total titulável } \\
\text { (\% ác. cítrico) }\end{array}$} & \multicolumn{3}{|c|}{ Relação SST/ATT } \\
\hline & Irrigado & Sequeiro & Média & Irrigado & Sequeiro & Média & Irrigado & Sequeiro & Média \\
\hline \multicolumn{10}{|l|}{ Época de poda } \\
\hline Novembro/2005 & $12,27 \mathrm{Ba}$ & $13,56 \mathrm{Aa}$ & $12,91 \mathrm{a}$ & $0,76 \mathrm{Aa}$ & $0,67 \mathrm{Ba}$ & $0,72 \mathrm{ab}$ & $16,38 \mathrm{Aa}$ & $20,26 \mathrm{Aa}$ & $18,32 \mathrm{ab}$ \\
\hline Dezembro/2005 & $12,39 \mathrm{Aa}$ & $12,26 \mathrm{Ab}$ & $12,33 \mathrm{a}$ & $0,74 \mathrm{Aa}$ & $0,72 \mathrm{Aa}$ & $0,73 \mathrm{a}$ & $16,67 \mathrm{Aa}$ & $17,12 \mathrm{Aa}$ & $16,89 \mathrm{~b}$ \\
\hline Janeiro/2006 & $11,60 \mathrm{Ba}$ & $13,84 \mathrm{Aa}$ & $12,72 \mathrm{a}$ & $0,63 \mathrm{Ab}$ & $0,65 \mathrm{Aa}$ & $0,64 c$ & $18,55 \mathrm{Aa}$ & $21,62 \mathrm{Aa}$ & $20,08 \mathrm{a}$ \\
\hline Fevereiro/2006 & $11,78 \mathrm{Ba}$ & $14,07 \mathrm{Aa}$ & $12,93 \mathrm{a}$ & $0,63 \mathrm{Bb}$ & $0,71 \mathrm{Aa}$ & $0,67 \mathrm{bc}$ & $18,95 \mathrm{Aa}$ & $20,05 \mathrm{Aa}$ & $19,50 \mathrm{a}$ \\
\hline \multicolumn{10}{|c|}{ Intensidade de poda } \\
\hline Curta & $11,84 \mathrm{Aa}$ & $13,35 \mathrm{Aa}$ & $12,61 \mathrm{a}$ & $0,70 \mathrm{Aa}$ & $0,68 \mathrm{Aa}$ & $0,69 \mathrm{a}$ & $17,42 \mathrm{Aa}$ & $19,67 \mathrm{Aa}$ & $18,54 \mathrm{a}$ \\
\hline Média & $12,30 \mathrm{Aa}$ & $13,30 \mathrm{Aa}$ & $12,79 \mathrm{a}$ & $0,70 \mathrm{Aa}$ & $0,71 \mathrm{Aa}$ & $0,70 \mathrm{a}$ & $17,74 \mathrm{Aa}$ & $19,18 \mathrm{Aa}$ & $18,46 \mathrm{a}$ \\
\hline Longa & $11,89 \mathrm{Aa}$ & $13,66 \mathrm{Aa}$ & $12,77 \mathrm{a}$ & $0,68 \mathrm{Aa}$ & $0,67 \mathrm{Aa}$ & $0,68 \mathrm{a}$ & $17,76 \mathrm{Aa}$ & $20,44 \mathrm{Aa}$ & $19,10 \mathrm{a}$ \\
\hline Média & $12,01 \mathrm{~A}$ & $13,43 \mathrm{~B}$ & 12,72 & $0,69 \mathrm{~A}$ & $0,69 \mathrm{~A}$ & 0,69 & $17,64 \mathrm{~B}$ & $19,76 \mathrm{~A}$ & 18,70 \\
\hline $\mathrm{CV}(\%)$ & & & 9,14 & & & 9,77 & & & 12,00 \\
\hline
\end{tabular}

${ }^{(1)}$ Médias seguidas por letras iguais, maiúsculas nas linhas e minúsculas nas colunas, dentro das mesmas épocas e intensidades de poda, não diferem entre si pelo teste de Tukey, a $5 \%$ de probabilidade.

Tabela 5. Características de qualidade dos frutos da goiabeira 'Paluma', colhidos no estádio maduro, em dois sistemas de cultivo, submetida a diferentes épocas e intensidades de poda de frutificação ${ }^{(1)}$.

\begin{tabular}{|c|c|c|c|c|c|c|c|c|c|}
\hline \multirow[t]{2}{*}{ Tratamento } & \multicolumn{3}{|c|}{$\begin{array}{c}\text { Teores de sólidos solúveis } \\
\text { ( }{ }^{\circ} \text { Brix) }\end{array}$} & \multicolumn{3}{|c|}{$\begin{array}{l}\text { Acidez total titulável } \\
\text { (\% ác. cítrico) }\end{array}$} & \multicolumn{3}{|c|}{ Relação SST/ATT } \\
\hline & Irrigado & Sequeiro & Média & Irrigado & Sequeiro & Média & Irrigado & Sequeiro & Média \\
\hline \multicolumn{10}{|l|}{ Época de poda } \\
\hline Novembro/2005 & $13,42 \mathrm{Aa}$ & $13,81 \mathrm{Aab}$ & $13,62 \mathrm{a}$ & $0,61 \mathrm{Aa}$ & $0,57 \mathrm{Aa}$ & $0,59 \mathrm{a}$ & $22,07 \mathrm{Aa}$ & $24,17 \mathrm{Aa}$ & $23,12 b$ \\
\hline Dezembro/2005 & $12,30 \mathrm{Aa}$ & $11,12 \mathrm{Bc}$ & $11,71 \mathrm{~b}$ & $0,63 \mathrm{Aa}$ & $0,59 \mathrm{Aa}$ & $0,61 \mathrm{a}$ & $19,75 \mathrm{Aa}$ & $19,10 \mathrm{Aa}$ & $19,43 \mathrm{c}$ \\
\hline Janeiro/2006 & $12,33 \mathrm{Aa}$ & $13,04 \mathrm{Ab}$ & $12,68 \mathrm{ab}$ & $0,52 \mathrm{Ab}$ & $0,55 \mathrm{Aa}$ & $0,53 b$ & $24,17 \mathrm{Aa}$ & $24,00 \mathrm{Aa}$ & 24,09 at \\
\hline Fevereiro/2006 & $12,27 \mathrm{Ba}$ & $14,63 \mathrm{Aa}$ & $13,45 \mathrm{a}$ & $0,48 \mathrm{Bb}$ & $0,56 \mathrm{Aa}$ & $0,52 \mathrm{~b}$ & $25,31 \mathrm{Aa}$ & $26,82 \mathrm{Aa}$ & $26,06 \mathrm{a}$ \\
\hline \multicolumn{10}{|c|}{ Intensidade de poda } \\
\hline Curta & $12,40 \mathrm{Aa}$ & $13,47 \mathrm{Aa}$ & $12,94 \mathrm{a}$ & $0,55 \mathrm{Aa}$ & $0,55 \mathrm{Aa}$ & $0,55 \mathrm{a}$ & $22,91 \mathrm{Aa}$ & $24,53 \mathrm{Aa}$ & $23,72 \mathrm{a}$ \\
\hline Média & $12,69 \mathrm{Aa}$ & $13,23 \mathrm{Aa}$ & $12,96 \mathrm{a}$ & $0,58 \mathrm{Aa}$ & $0,56 \mathrm{Aa}$ & $0,57 \mathrm{a}$ & $22,51 \mathrm{Aa}$ & $24,13 \mathrm{Aa}$ & $23,32 \mathrm{a}$ \\
\hline Longa & $12,64 \mathrm{Aa}$ & $12,76 \mathrm{Aa}$ & $12,71 \mathrm{a}$ & $0,56 \mathrm{Aa}$ & $0,58 \mathrm{Aa}$ & $0,57 \mathrm{a}$ & $23,06 \mathrm{Aa}$ & $21,92 \mathrm{Aa}$ & $22,49 \mathrm{a}$ \\
\hline Média & $12,58 \mathrm{~A}$ & $13,15 \mathrm{~A}$ & 12,87 & $0,56 \mathrm{~A}$ & $0,57 \mathrm{~A}$ & 0,56 & $22,82 \mathrm{~A}$ & $23,53 \mathrm{~A}$ & 23,18 \\
\hline CV (\%) & & & 9,19 & & & 9,38 & & & 13,85 \\
\hline
\end{tabular}

${ }^{(1)}$ Médias seguidas por letras iguais, maiúsculas nas linhas e minúsculas nas colunas, dentro das mesmas épocas e intensidades de poda, não diferem entre si pelo teste de Tukey, a $5 \%$ de probabilidade. 
Quando os resultados de qualidade dos frutos foram comparados isoladamente, dentro de cada intensidade de poda, não houve diferença no teor de SST entre os estádios de maturação estudados, resultado semelhante aos obtidos com a goiaba 'Kumagai' (Cavalini et al., 2006) e 'Pedro Sato' (Azzolini et al., 2004). Quanto à ATT e à relação SST/ATT, houve diferença entre os estádios de maturação, em que as médias de ATT foram de 0,69 e 0,56\%, e as de relação SST/ATT foram de 18,70 e 23,18 nos frutos "de vez" e maduros, respectivamente. Mercado-Silva et al. (1998), Azzolini et al. (2004) e Cavalini et al. (2006) também verificaram que à medida que as goiabas 'Média China', 'Pedro Sato' e 'Paluma' amadureceram, a ATT decresceu, o que foi atribuído ao fato de os ácidos orgânicos representarem um dos principais substratos utilizados nos processos respiratórios, durante o amadurecimento.

\section{Conclusões}

1. A irrigação, a época e a intensidade de poda de frutificação afetam a produção, o número de frutos colhidos e o peso médio dos frutos da goiabeira 'Paluma'.

2. A irrigação na goiabeira 'Paluma' eleva a produção, o número de frutos por planta e o peso médio dos frutos.

3. Plantas submetidas à poda curta apresentam menor produção e número de frutos por planta, entretanto produzem frutos mais pesados.

4. A produção de frutos mais pesados é favorecida, independentemente da intensidade da poda de frutificação, quando esta é realizada em dezembro.

5. A intensidade da poda de frutificação não influencia os teores de SST, ATT e relação SST/ATT dos frutos, que são, porém, influenciados pelo sistema de cultivo e pela época de poda.

\section{Agradecimentos}

À Fundação de Apoio à Ciência e Tecnologia do Espírito Santo (Fapes), pelo apoio financeiro; ao Agrôn. Rossini Brito Pereira e aos produtores rurais Oribes Storch e Carlito Corrêa Nascimento, pelo apoio à realização do experimento; ao Pesquisador José Mauro de Souza Balbino, pelo apoio nas realizações das análises químicas dos frutos.

\section{Referências}

AZZOLINI, M.; JACOMINO, A.P.; BRON, I.U. Índices para avaliar qualidade pós-colheita de goiabas em diferentes estádios de maturação. Pesquisa Agropecuária Brasileira, v.39, p.139-145, 2004.

CAVALINI, F.C.; JACOMINO, A.P.; LOCHOSKI, M.A.; KLUGE, R.A.; ORTEGA, E.M.M. Maturity indexes for 'Kumagai' and 'Paluma' guavas. Revista Brasileira de Fruticultura, v.28, p.176179, 2006.

CHIRINOS-TORRES, D.; LARREAL, M.M.; PALMAR, C.G.; LARA, C. Crescimento y producción de plantas de guayabo (Psidium guajava L.) bajo riego e incidencia de frutos enfermos. Revista de la Facultad de Agronomía, v.23, p.60-69, 2006.

CHOUDHURY, M.M.; ARAÚJO, J.L.P.; GONZAGA NETO, L.; RESENDE, J.M.; COSTA, T.S.; SCAGGIANTE, G. Goiaba: póscolheita. Petrolina: Embrapa Semi-Árido; Brasília: Embrapa Informação Tecnológica, 2001. 45p. (Frutas do Brasil, 17).

GARCIA, J.L.; PÉREZ-PÉREZ, R. Effect of pruning and harvesting methods on guava yields. Journal of Agriculture of the University of Puerto Rico, v.61, p.148-151, 1977.

GONZAGA NETO, L.; LEODIDO, J.M.C.; SILVA, E.E.G. Raleamento de frutos da goiabeira cv. Rica em Juazeiro, BA, Brasil. Pesquisa Agropecuária Brasileira, v.32, p.1281-1286, 1997.

GONZAGA NETO, L.; SOARES, J.M.; TEIXEIRA, A.H.C.; MOURA, M.S.B. Goiaba: produção: aspectos técnicos. Petrolina: Embrapa Semi-Árido; Brasília: Embrapa Informação Tecnológica, 2001. 72p. (Frutas do Brasil, 17).

GONZALEZ, G.; SOURD, Y.D. Ensayo de poda en cinco cultivares de guayaba (Psidium guajava). Ciencia y Técnica en la Agricultura: Cítricos y Otros Frutales, v.5, p.39-51, 1982.

HOQUE, A.; AZAD, A.K.; HOSSAIN, A.K.M.A. Effect of leaffruit ratio on size, yield and quality of fruits of guava (Psidium guajava L.) cv. Kazi Piara. Thai Journal of Agricultural Science, v.22, p.347-353, 1989.

LARCHER, W. Ecofisiologia vegetal. PRADO, C.H.B.A. (Trad.). São Carlos: RiMa Artes e Textos, 2000. 531p.

LIMA, M.A.C.; ASSIS, J.S.; GONZAGA NETO, L. Caracterização dos frutos de goiabeira e seleção de cultivares na região do Submédio São Francisco. Revista Brasileira de Fruticultura, v.24, p.273276, 2002.

LOPES, J.G.V.; MANICA, I.; KOLLER, O.C.; RIBOLDI, J. Efecto de seis épocas de poda en la producción de guayabo (Psidium guajava L.) en Novo Hamburgo, Rio Grande do Sul, Brasil. Fruits, v.39, p.393-397, 1984.

LÖTTER, J.V. Vegetative and reproductive habit of the guava (Psidium guajava cv. Fan Retief) in relation to pruning methods. Acta Horticulturae, v.275, p.229-238, 1990.

MANICA, I.; ICUMA, I.M.; JUNQUEIRA, N.T.V.; SALVADOR, J.O.; MOREIRA, A.; MALAVOLTA, E. Goiaba. Porto Alegre: Ed. Cinco Continentes, 2000. 374p. (Fruticultura tropical, 6).

MERCADO-SILVA, E.; BAUTISTA, B.P.; VELASCO, M.A.G. Fruit development, harvest index and ripening changes of guavas produced in Central Mexico. Postharvest Biology and Technology, v.13, p.143-150, 1998. 
MIKA, A. Physiological responses of fruit trees to pruning. Horticultural Reviews, v.8, p.337-378, 1986.

NATALE, W.; COUTINHO, E.L.M.; BOARETTO, A.E.; PEREIRA, F.M. Goiabeira: calagem e adubação. Jaboticabal: Funep, 1996. 22p.

PEREIRA, F.M.; NACHTIGAL, J.C. Goiabeira. In: BRUCKNER, C.H. (Ed.). Melhoramento de fruteiras tropicais. Viçosa: Universidade Federal de Viçosa, 2002. p.267-289.

PEREIRA, W.E. Desenvolvimento dos ramos e frutos de seis variedades de goiabeira (Psidium guajava $\mathrm{L}$.) no período seco do ano. 1996. 48p. Tese (Mestrado) - Universidade Federal de Viçosa, Viçosa.

PIZA JÚNIOR, C.T. A poda da goiabeira de mesa. Campinas: Coordenadoria de Assistência Técnica Integral, 1994. 30p. (Boletim técnico, 222).

QUIJADA, O.; ARAUJO, F.; CORZO, P. Efecto de la poda y la cianamida hidrogenada sobre la brotación, fructificación, producción y calidad de frutos del guayabo (Psidium guajava L.) en el Municipio del Estado Zulia. Revista de la Facultad de Agronomía, v.16, p.276-290, 1999.
SILVA, R.P.; DANTAS, G.G.; NAVES, R.V.; CUNHA, M.G. Comportamento fenológico de videira, cultivar Patrícia em diferentes épocas de poda de frutificação em Goiás. Bragantia, v.65, p.399406, 2006.

SINGH, G.; RAJAN, S.; PANDEY, D.; SINGH, A.K. Effect of soilmoisture stress on water relation by plant and cropping behaviour in guava (Psidium guajava). Indian Journal of Agricultural Sciences, v.67, p.303-306, 1997.

SINGH, G.; SINGH, A.K.; RAJAN, S. Influence of pruning date on fruit of guava (Psidium guajava L.) under subtropics. Journal of Applied Horticulture, v.3, p.37-40, 2001.

SOUSA, E.F. Funções de produção da cana-de-açúcar e da goiabeira em relação à irrigação. 1997. 106p. Tese (Doutorado) - Universidade Estadual do Norte Fluminense Darcy Ribeiro, Campos dos Goytacazes.

UFV. SAEG: sistema para análises estatísticas. Versão 9.0. Viçosa, 2005. 1 CD-ROM.

YUNUS, N. Effect of intensity of training and pruning on growth, yield and quality of guava var. JP-1. Acta Horticulturae, v.322, p.291-292, 1991.

Recebido em 16 de fevereiro de 2007 e aprovado em 27 de abril de 2007 